\title{
THE SPACEBORNE IMAGING SPECTROMETER DESIS: DATA ACCESS AND SCIENTIFIC APPLICATIONS
}

\author{
R. Müller ${ }^{\mathrm{a}}$, K. Alonso ${ }^{\mathrm{a}}$, M. Bachmann ${ }^{\mathrm{a}}$, K. Burch ${ }^{\mathrm{d}}$, E. Carmona ${ }^{\mathrm{a}}$, D. Cerra ${ }^{\mathrm{a}}$, D. Dietrich ${ }^{\mathrm{a}}$, P. Gege ${ }^{\mathrm{a}}$, \\ H. Lester ${ }^{\mathrm{e}}$, U. Heiden ${ }^{\mathrm{a}}$, S. Holzwarth ${ }^{\mathrm{a}}$, U. Knodt ${ }^{\mathrm{b}}$, D. Krutz ${ }^{\mathrm{c}}$, D. Marshalla ${ }^{\mathrm{a}}$, M. Pato ${ }^{\mathrm{a}}$, R. de los Reyes ${ }^{\mathrm{a}}$, \\ P. Reinartz ${ }^{\mathrm{a}}$, M. Tegler
}

${ }^{a}$ German Aerospace Center (DLR), Earth Observation Center, 82234 Wessling, Germany

${ }^{\mathrm{b}}$ German Aerospace Center (DLR), Strategie und Vernetzungen, Linder Höhe, 51147 Köln, Germany

${ }^{\mathrm{c}}$ German Aerospace Center (DLR), Optical Sensor Systems, Rutherfordstraße, 12489 Berlin, Germany

e Teledyne Brown Engineering (TBE), 300 Sparkman Drive, Huntsville, AL 35805, USA

${ }^{\mathrm{d}}$ Innovative Imaging and Research, Corp. (I2R), Stennis Space Center, MS 39529, USA

\section{INTRODUCTION}

The DLR Earth Sensing Imaging Spectrometer (DESIS) is a space-based instrument installed and operated on the International Space Station (ISS) [1]. This space mission is the achievement of the collaboration between the German Aerospace Center (DLR) and the US company Teledyne Brown Engineering (TBE). DLR has developed the instrument and the software for data processing [2], while TBE provides the Multi-User System for Earth Sensing (MUSES) platform, where DESIS is installed, and the infrastructure for operation and data tasking [3].

The main performance parameters of the DESIS instrument are summarized in Table 1. DESIS is equipped with an on-board calibration unit and a rotating pointing mirror (POI). The POI can change the line of sight $\pm 15^{\circ}$ in the forward/backward direction (independently of the MUSES orientation) allowing multi-angular measurements of the same area on ground within an overflight.

\begin{tabular}{|l|l|}
\hline Parameter & \\
\hline Focal length & $320 \mathrm{~mm}$ \\
\hline FoV & $4.1^{\circ}$ \\
\hline IFoV & $0.004^{\circ}$ \\
\hline GSD & $30 \mathrm{~m}$ \\
\hline Spatial pixels & 1024 \\
\hline Swath & $30 \mathrm{~km}$ \\
\hline Spectral range & $400 \mathrm{~nm}-1000 \mathrm{~nm}$ \\
\hline Spectral channels & 235 (for no binning) \\
\hline Spectral sampling & $2.55 \mathrm{~nm}$ (for no binning) \\
\hline Spectral binning modes & no, 2, 3, 4 \\
\hline SNR (albedo 0.3, 550nm) & 195 (no binning) \\
\hline Radio. Linearity & 386 (binning 4) \\
\hline Radio. Resolution & $>95 \%(10 \%-90 \%$ Full \\
\hline
\end{tabular}

\begin{tabular}{|l|l|}
\hline MTF at Nyquist & $>20 \%$ \\
\hline FWHM & $\sim 3.5 \mathrm{~nm}$ \\
\hline Max. frame rate & $232 \mathrm{~Hz}$ (Rolling Shutter) \\
\hline
\end{tabular}

Table 1 Performance parameters of the DESIS instrument.

About five years after the mission's kick-off, the DESIS spectrometer was integrated into MUSES in August 2018, marking the start of the commissioning phase. The DESIS inorbit functional tests were successful and the DLR-built processing chains installed at DLR and TBE are operationally generating the DESIS products listed in Table 2.

\begin{tabular}{|c|c|c|}
\hline $\begin{array}{l}\text { Product } \\
\text { Type }\end{array}$ & Description & $\begin{array}{l}\text { Order } \\
\text { Parameters }\end{array}$ \\
\hline L1B & $\begin{array}{l}\text { Radiometric and sensor specific } \\
\text { corrected data. Top of Atmosphere } \\
\text { (TOA) radiance All metadata } \\
\text { attached for further processing [4] }\end{array}$ & $\begin{array}{l}\text { Spectral } \\
\text { Binning }\end{array}$ \\
\hline L1C & $\begin{array}{l}\text { L1B data ortho-rectified and } \\
\text { resampled to a specified grid } \\
\rightarrow \quad \text { using global SRTM } 1 \text { arcsec } \\
\\
\Rightarrow \quad \begin{array}{l}\text { DEM for terrain correction } \\
\text { using global Landsat ETM+ } \\
\text { references for sensor model } \\
\text { refinement [4][5] }\end{array}\end{array}$ & $\begin{array}{l}\text { Map } \\
\text { Projection } \\
\text { Resampling }\end{array}$ \\
\hline L2A & $\begin{array}{l}\text { L1C data atmospherically corrected } \\
\text { (BOA reflectance) } \\
\rightarrow \quad \text { using global SRTM } 1 \text { arcsec } \\
\text { DEM for terrain correction } \\
\rightarrow \quad \text { generating several masks } \\
\text { (water, land, cloud, cloud } \\
\text { shadow over land, haze over } \\
\text { land, haze over water, Aerosol } \\
\text { Optical Thickness (AOT), } \\
\text { water vapor) [4][6][7][8] }\end{array}$ & $\begin{array}{l}\text { Terrain } \\
\text { Correction } \\
\text { Ozone } \\
\text { Column }\end{array}$ \\
\hline
\end{tabular}

Table 2: DESIS products and processing parameters 
In October 2019 the mission entered into operational phase, starting the distribution of the data to the scientific and commercial community. The data quality as evaluated during the commissioning phase is summarized as follows [4]:

- Absolute radiometric calibration is well within $\sim 10 \%$ at the Top-of-Atmosphere (TOA) radiance and TOA reflectance level when validated against RadCalNet [9], Sentinel-2 and Landsat-8.

- Spectral calibration after smile correction is typically better than $\sim 0.5 \mathrm{~nm}$, and always within $1 / 3$ of a spectral pixel.

- SNR is greater than 200 at 0.3 albedo, mid-latitude summer, $45^{\circ}$ solar elevation, rural aerosol and $23 \mathrm{~km}$ visibility (investigated at five bands at $443 \mathrm{~nm}, 482 \mathrm{~nm}$, $562 \mathrm{~nm}, 655 \mathrm{~nm}, 865 \mathrm{~nm}$ ) and agrees with groundbased measurements

- MTF@Nyquist (across track) is about 0.3 - 0.4

- Geometric accuracy with respect to reference is $\sim 20 \mathrm{~m}$ ( $<1$ pixel) linear RMSE in the case that GCPs can be derived from image-to-image matching; otherwise RMSE is $300-500 \mathrm{~m}$.

- $\quad$ Agreement of Bottom-of-Atmosphere (BOA) reflectance within $\sim 10 \%$ to RadCalNet [9], Sentinel-2 and field campaign data from Pinnacles site (Australia).

In a continuous monitoring process, the data quality is controlled and, if necessary, the calibration algorithms and tables are adjusted.

\section{DATA ACCESS}

DESIS products are available from two data access portals. The first one is the Earth Sensor Portal (ESP) at Teledyne, which allows to task new data acquisitions (including standing tasking orders), order data from the catalogue $(54,438$ products in the archive @ Jan. 2021 corresponding to $\sim 10 \%$ of the land surface of the earth) and process data for commercial uses. The second one is the Earth Observation (EOWEB) GeoPortal, which allows to order data from the DLR catalogue ( 7,853 products in the archive @ Jan. 2021) and to process data for scientific uses. The data processing chains are identical at both Ground Segments. A scientific user can only receive data from EOWEB, but is able to use the ESP for tasking and catalogue orders. Once the user has selected data from ESP the products are automatically transferred to EOWEB, which serves as platform to process the data toward higher product levels. Access to the portals needs a user registration. The EOWEB archive hosts data already ordered by other users. These data are freely available and open for scientific purposes and can be downloaded by any user without having submitted a scientific proposal. In order to search for the data any EOWEB account can be used. However, downloading data requires an EOWEB account. More information can be found on the official DLR portal (see www.dlr.de/eoc/desktopdefault.aspx/tabid-13614 ) which, in addition to an overview of the DESIS mission, contains information of the

- $\quad$ product specification,

- algorithms applied to the data,

- data announcement (including a proposal template),

- frequently asked questions,

- Point-of-Contacts to get data access rights

and the TBE portal (see tbe.com/geospatial/MUSES ), which provides information on the commercial activities using DESIS data.

The DESIS products are provided in Geotiff format with XML metadata, making them compatible with most image visualization and analysis programs. In addition, DESIS products are explicitly supported by

- the EnMAP-Box, which is a free and open source Python plug-in for QGIS and contains a product reader for DESIS images. (see www.enmap.org/data_tools/enmapbox/ )

- the ENVI Software, which brings in the radiance gains and offsets and all relevant metadata. (see www.13harrisgeospatial.com/ )

\section{SCIENTIFIC APPLICATIONS}

Since the start of the operational phase, a number of scientific proposals from all over the world have been received by the DLR Science Team.

\section{Scientific activities worldwide}

Currently (15 $5^{\text {th }}$ January 2021) a total of 41 scientific proposals have been submitted from external users worldwide, with the topics listed in Table 3

\begin{tabular}{|l|c|}
\hline Topic & $\begin{array}{l}\text { number of } \\
\text { proposals }\end{array}$ \\
\hline $\begin{array}{l}\text { Urban Thematic Exploitation \& } \\
\text { Material Composition }\end{array}$ & 2 \\
\hline Landcover \& vegetation & 5 \\
\hline Water Resources & 7 \\
\hline Ocean Applications & 4 \\
\hline Coastal Applications & 5 \\
\hline Calibration & 1 \\
\hline Natural Resources & 8 \\
\hline Geology & 3 \\
\hline Biodiversity & 2 \\
\hline $\begin{array}{l}\text { Others (e.g. methods development, data } \\
\text { fusion) }\end{array}$ & 4 \\
\hline
\end{tabular}

Table 3: External DESIS proposals $\left(15^{\text {th }}\right.$ Jan 2021)

\section{Scientific activities at DLR}

Fractional vegetation cover for environmental modeling Fractional vegetation cover (fCover), the percentage of vegetation covering an area of land, plays an integral part in 
the exchange of carbon, water and energy at the land surface, and is an important parameter in environmental applications such as soil erosion and dynamic vegetation modeling. Using DESIS data, abundance maps can be derived for (1) photosynthetically active vegetation (PV), (2) nonphotosynthetically active vegetation (NPV), and (3) bare soil (BS). The fCover abundance maps are made by performing $\mu$ MESMA unmixing [10] on each pixel from an endmember library. Endmembers for PV, NPV ad BS are derived from the DESIS scene using the Spatial-Spectral Endmember Extraction (SSEE [11]) approach and a random forest classifier. Figure 1 shows an example of the fCover results from a DESIS observation of Camarena, central Spain. The measured fractional abundances can then be compared to measurements taken in the field for validation.
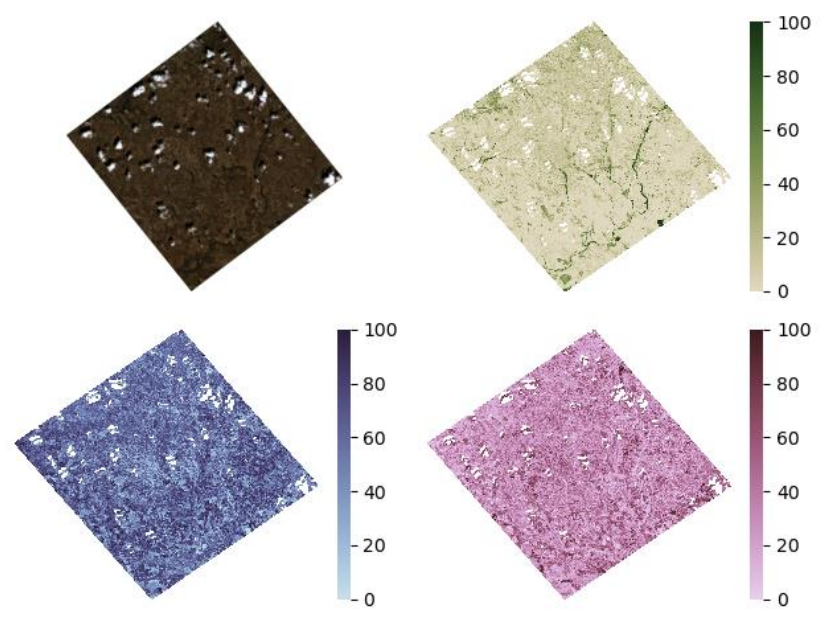

Figure 1: Fractional vegetation cover results from a DESIS observation of Camarena, central Spain. Top left: RGB DESIS image. Top right: abundance map of green vegetation (PV) cover (\%). Bottom left: abundance map of dry vegetation (NPV) cover (\%). Bottom right: abundance map of bare soil (BS) cover (\%).

\section{$\underline{\text { Sun-induced fluorescence maps }}$}

In this project DESIS data in combination with cutting-edge artificial intelligence methods are being used for vegetation mapping to retrieve the fluorescence signals emitted by the vegetation. This will open the possibility to generate global sun-induced fluorescence maps, which will play a key role in monitoring vegetation health worldwide

\section{Bathymetry for archeology}

DESIS data are used for aquatic remote sensing of water quality and shallow-water bathymetry. Figure 2 shows an example from Cyprus [12]. In support of underwater archaeology and Marine spatial planning, bathymetry was derived for an extended area around the submerged harbor of Amathus, which is a sensitive cultural heritage site. The derived water depths were validated by comparison with depth measurements using multi-beam echo sounders and airborne LiDAR. The scatterplot of Figure 2 shows that the root-mean square error is comparable to the uncertainty of the reference data $( \pm 0.5 \mathrm{~m})$.

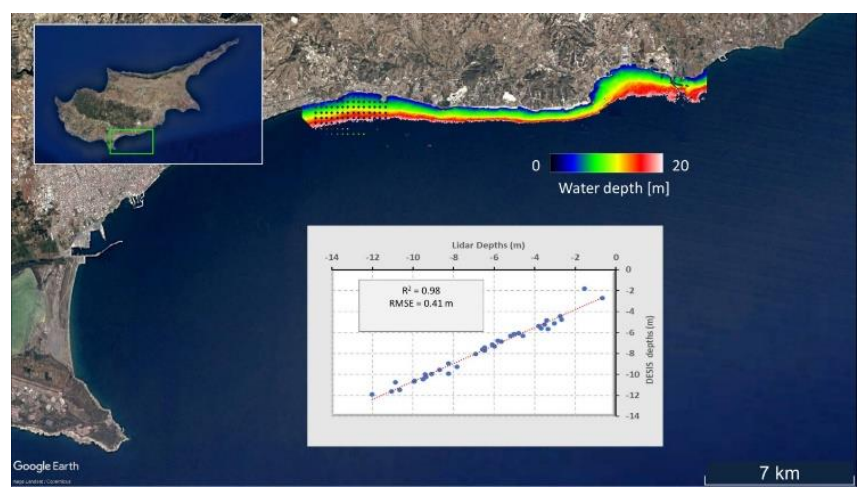

Figure 2: DESIS-derived bathymetry at the South coast of Cyprus. The dots in the depth map represent the locations of the validation measurements shown in the insert.

$\underline{\text { Standard Level } 3 \text { Products }}$

Currently, DLR is expanding the DESIS product range in the areas of

- $\quad$ Forest Products like leaf pigments, greenness, canopy water content [13]

- Soil Products like implementing the Soil Composite Mapping Processor (SCMaP) [14]

- Water Products like Phytoplankton concentration, Total Suspended Matter (TSM), Colored dissolved organic matter (CDOM) [15]

\section{OUTLOOK}

Future activities include mutual support, such as crosscalibration or data simulation, with Chime, EnMAP, PRISMA and HISUI.

In particular, support and cooperation with the CHIME mission is an essential part of future work [16], which includes the following

o DESIS data are being used for the development and testing of new earth observation products relating to the CHIME mission. In 2020, DESIS data has been acquired for most of the CHIME preparatory mission sites across Europe from spring until the end of October. This data is available on a free and open basis. Further acquisitions are planned for 2021 supported by field and airborne campaigns organized by the respective site PIs. Thus, the resulting multitemporal data sets are essential to develop and test L3 and L4 information products for estimating stress and photosynthetic output of plants, quantifying the fertility and fertilizer requirements of soils as well as assessing the character and degree of water body eutrophication to just name a few applications. 
o Another goal is to estimate the volume of data expected from the future hyperspectral Sentinel mission CHIME. It will considerably exceed the amount of data acquired from the multispectral Sentinel-2 mission, in operation since 2015. Sentinel-2 records Earth's surface in 14 different spectral channels, whereas over 200 will be recorded in the CHIME mission. The anticipated data volume poses a challenge for data transfer as well as for data processing and storage, which requires new, intelligent technologies.

\section{BIBLIOGRAPHY}

[1] Krutz, D.; Müller, R.; Knodt, U.; Günther, B.; Walter, I.; Sebastian, I.; Säuberlich, T.; Reulke, R.; Carmona, E.; Eckardt, A.; Venus, H.; Fischer, C.; Zender, B.; Arloth, S.; Lieder, M.; Neidhardt, M.; Grote, U.; Schrandt, F.; Gelmi, S.; Wojtkowiak, A. The Instrument Design of the DLR Earth Sensing Imaging Spectrometer (DESIS). Sensors 2019, 19, 1622.

[2] Müller, R., Avbelj, J., Carmona, E., Eckardt, A., et al., The new hyperspectral sensor desis on the multi-payload platform muses installed on the ISS. International Archives of the Photogrammetry, Remote Sensing \& Spatial Information Sciences 41. 2016.

[3] Perkins, R., Krutz, D., Müller, R., Carmona, E., Griffin, R., Graham, L., Miller, R. (2016): Teledyne's Multi-User System for Earth Sensing (MUSES), JACIE (Joint Agency Commercial Imagery Evaluation) Workshop, Fort Worth, Texas, USA, April 11-15, 2016

[4] Alonso, K.; Bachmann, M.; Burch, K.; Carmona, E.; Cerra, D.; de los Reyes, R.; Dietrich, D.; Heiden, U.; Hölderlin, A.; Ickes, J.; Knodt, U.; Krutz, D.; Lester, H.; Müller, R.; Pagnutti, M.; Reinartz, P.; Richter, R.; Ryan, R.; Sebastian, I.; Tegler, M. Data Products, Quality and Validation of the DLR Earth Sensing Imaging Spectrometer (DESIS). Sensors 2019, 19, 4471.

[5] Müller, R., Krauß, T., Schneider, M., Reinartz, P., Automated Georeferencing of Optical Satellite Data with Integrated Sensor Model Improvement. Photogrammetric Engineering and Remote Sensing (PE\&RS), 78 (1), Pages 61- 74. American Society for Photogrammetry and Remote Sensing. ISSN 0099-1112. 2012.

[6] de los Reyes, R.; Langheinrich, M.; Schwind, P.; Richter, R.; Pflug, B.; Bachmann, M.; Müller, R.; Carmona, E.; Zekoll, V.; Reinartz, P. PACO: Python-Based Atmospheric Correction. Sensors 2020, 20, 1428
[7] Richter, R., A spatially adaptive fast atmospheric correction algorithm. International Journal of Remote Sensing, 17(6), pp. 1201-1214. 1996

[8] Richter, R., Atmospheric Correction Methods for Optical Remote Sensing Imagery of Land. In: Advances in Environmental Remote Sensing Remote Sensing Applications. Taylor \& Francis, London. Seiten 161-172. ISBN 978-1-4200- 9175-5. 2011.

[9] Bouvet, M.; Thome, K.; Berthelot, B.; Bialek, A.; Czapla-Myers, J.; Fox, N.P.; Goryl, P.; Henry, P.; Ma, L.; Marcq, S.; et al. RadCalNet: A Radiometric Calibration Network for Earth Observing Imagers Operating in the Visible to Shortwave Infrared Spectral Range. Remote Sens. 2019, 11, doi:10.3390/rs11202401.

[10] Bachmann, M. UR. "Automatisierte Ableitung von bodenbedeckungsgraden durch MESMA-Entmischung." (2007).

[11] Rogge, D., Bachmann, M., Rivard, B., Feng, J. (2012): Spatial Sub-Sampling Using Local Endmembers for Adapting OSP and SSEE for Large-Scale Hyperspectral Surveys. IEEE Journal of Selected Topics in Applied Earth Observations and Remote Sensing, 5 (1).

[12] Cerra, D., Gege, P., Evagorou, E., Agapiou, A., de los Reyes, R. (2020): Monitoring Marine Areas from Space: the Case of the Submerged Harbor of Amathus. Proc.

EuroMed2020

[13] Holzwarth, S., Thonfeld, F., Abdullahi, S., Asam, S., Da Ponte, E., Gessner, U., Huth, J., Kraus, T., Leutner, B., Künzer, C. (2020): Earth Observation Based Monitoring of Forests in Germany: A Review. Remote Sensing, Seiten 143. Multidisciplinary Digital Publishing Institute (MDPI). DOI: $10.3390 /$ rs12213570 ISSN 2072-429

[14] Rogge, D., Bauer, A., Zeidler, J., Müller, A., Esch, T., Heiden, U. (2018): Building an exposed soil composite processor $(\mathrm{SCMaP})$ for mapping spatial and temporal characteristics of soils with Landsat imagery (1984-2014). Remote Sensing of Environment, 205, Seiten 1-17. Elsevier. DOI: 10.1016/j.rse.2017.11.004 ISSN 0034-425

[15] Gege, P. (2014): WASI-2D - A software tool for regionally optimized analysis of imaging spectrometer data from deep and shallow waters. Computers \& Geosciences, 62, Seiten 208-215. Elsevier. DOI:

10.1016/j.cageo.2013.07.022 ISSN 0098-3004

[16] https://www.dlr.de/eoc/en/desktopdefault.aspx/tabid14195/24618_read-65962/ last access 15.01.2021 